\title{
PREVALÊNCIA DE ALTERAÇÕES UTERINAS E TUBÁRIAS NA HISTEROSSALPINGOGRAFIA EM MULHERES INFÉRTEIS - ESTUDO DE 48 CASOS*
}

\author{
Juliano Adams Pérez ${ }^{1}$, Marvin Nessi Maurer ${ }^{2}$, Marcelo de Abreu ${ }^{3}$, Letícia Henneman Pitrez ${ }^{3}$, \\ Roberto Campos Pellanda ${ }^{3}$, Sérgio Augusto Cardoso Maurer ${ }^{4}$, Álvaro Porto Alegre Furtado \\ Carlos Horácio Genro ${ }^{6}$
}

Resumo A histerossalpingografia é um exame realizado para avaliação da anatomia uterina e da permeabilidade tubária, característica esta que torna a pesquisa de causa de infertilidade primária ou secundária sua principal indicação. Este trabalho se propôs a estudar a prevalência de alteraçōes na histerossalpingografia em pacientes com infertilidade. Para tal, foram alocadas todas as pacientes que se submeteram ao exame, num período de quatro meses. Entre as 48 pacientes estudadas, 36 apresentavam infertilidade primária e 12, infertilidade secundária. As pacientes com infertilidade primária apresentaram maior índice de malformaçōes uterinas, enquanto as pacientes com infertilidade secundária apresentaram obstrução tubária como alteração mais freqüente. Não ocorreu nenhuma intercorrência significativa durante a realização dos exames. 0 trabalho permite afirmar que este exame é muito útil na pesquisa de infertilidade, uma vez que, freqüentemente, diagnostica alteraçōes importantes, sendo um exame barato e de raras complicaçōes.

Unitermos: Histerossalpingografia. Infertilidade.

\begin{abstract}
Prevalence of uterine and tubal abnormalities in infertile women - a study of 48 cases.
Hysterosalpingography is a technique used for the evaluation of the uterine anatomy and tubal patency and consequently it is primarily indicated for the diagnosis of infertility. The aim of this study was to establish the prevalence of the abnormalities observed on the hysterosalpingograms of infertile patients. All patients that underwent hysterosalpingographic evaluation in a period of four months were allocated. Of the 48 patients studied, 36 presented primary infertility and 12 presented secondary infertility. The patients with primary infertility presented a higher rate of uterine malformations whereas the patients with secondary infertility presented more often tubal obstruction. There were no significant complications during the hysterosalpingograms. This study demonstrates that hysterosalpingography is very useful for the evaluation of infertility, as it frequently diagnoses relevant abnormalities, it is an inexpensive technique and the complications are very rare.

Key words: Hysterosalpingography. Infertility.
\end{abstract}

\section{INTRODUÇÃO}

A histerossalpingografia é um exame realizado por intermédio da injeção de contraste no colo uterino, com o objetivo de opacificar o útero e as trompas uterinas, avaliando, com isso, a arquite-

* Trabalho realizado no Serviço de Radiologia do Hospi tal de Clínicas de Porto Alegre (HCPA), Porto Alegre, RS.

1. Acadêmico da Faculdade de Medicina da Pontifícia Universidade Católica do Rio Grande do Sul.

2. Acadêmico da Faculdade de Medicina da Universidade de Caxias do Sul, RS.

3. Médicos Residentes do Serviço de Radiologia do HCPA.

4. Médico Radiologista do Serviço de Radiologia do HCPA

5. Médico Radiologista, Chefe do Serviço de Radiologia do HCPA, Professor da Faculdade de Medicina da Universidade Federal do Rio Grande do Sul (UFRGS).

6. Médico Radiologista, Professor da Faculdade de Medicina da UFRGS.

Endereço para correspondência: Juliano Adams Pérez. Rua Vicente Lopes dos Santos, 200, apto. 502, Bairro Menino Deus. Porto Alegre, RS, 90130-140.

Aceito para publicação em 9/8/2000 tura interna do trato reprodutivo feminino ${ }^{(1,2)}$. Pode, portanto, fornecer valiosas informações em relação a anormalidades tubárias e uterinas em pacientes com infertilidade primária ou secundária, abortos recorrentes ou monitorização de cirurgia tubária ${ }^{(3)}$. Este exame faz parte da rotina de investigação de infertilidade, o que o torna de grande importância, uma vez que a maioria dos estudos em países industrializados afirma que aproximadamente $15 \%$ de todos os casais apresentarão infertilidade primária ou secundária em algum momento de suas vidas reprodutivas ${ }^{(4,5)}$.

\section{MATERIAIS E MÉTODOS}

Realizamos um estudo de prevalência de pacientes com infertilidade. Para tal, reunimos uma amostra que consis- tiu de todas as pacientes que, a partir da queixa de infertilidade, realizaram histerossalpingografia no Hospital de Clínicas de Porto Alegre, no período de março a julho de 1999.

Elaboramos, também, um protocolo constando de dados de identificação, história clínica, diagnóstico e seguimento clínico, sendo os exames interpretados por dois radiologistas experientes. As medidas de prevalência dos achados e cruzamento de dados foram feitas no programa estatístico EPI Info 6.

A técnica utilizada para a realização inicia-se com a radiografia simples da pelve, em ântero-posterior, e é seguida pela antissepsia do trato genital externo, com posterior introdução do espéculo para a visibilização do colo e antissepsia interna. $\mathrm{O}$ antisséptico utilizado é o iodofor aquoso. 
Após a assepsia, faz-se a fixação do lábio superior do colo uterino com uma pinça Pozi. Utiliza-se para a injeção de contraste iodado puro uma seringa de vidro de $20 \mathrm{ml}$ conectada a uma cânula, condutor metálico e oliva plástica adequada ao orifício cervical externo. O contraste utilizado é o iodado puro Hypaque, sendo que, no caso de a paciente apresentar história de alergia ou fatores de risco que dificultem o tratamento de reações ao meio de contraste utilizado, realizamos o exame com contraste nãoiônico (Omnipaque). Realiza-se a injeção de contraste simultaneamente a leve tração do colo, iniciando-se, geralmente, com infusão de 15 a $20 \mathrm{ml}$ de contraste. O médico executor deve ser cuidadoso, injetando o contraste cautelosamente, sem resistência, tendo sido retirado todo o ar do sistema. Médicos e auxiliares estão preparados para o manejo de reações ao meio de contraste. Há um carro de parada em uma sala do serviço, com medicação e material adequados para o tratamento das possíveis complicações. São realizadas, então, cinco radiografias orientadas pela radioscopia. A primeira é feita em ântero-posterior, quando há preenchimento do útero por contraste; a segunda, quando as trompas se opacificam e há extravasamento do contraste para a cavidade peritoneal. Em seguida, são realizadas incidências em oblíqua posterior direita e esquerda. A última radiografia é feita dez minutos depois da retirada do material ${ }^{(3)}$.

\section{RESULTADOS}

Das 48 pacientes incluídas em nosso estudo, 36 apresentavam queixa de infertilidade primária, sendo que, entre estas, uma possuía história de endometriose e outra, de mioma. Doze pacientes realizaram o exame devido a infertilidade secundária e duas destas apresentavam passado de gestação ectópica e outras duas de abortos de repetição.

Apenas uma paciente, com infertilidade primária e endometriose no passado, relatou história de doença inflamatória pélvica confirmada.

Em relação ao laudo, este foi normal em 30 ocasiões.

Tabela 1 Distribuição dos achados alterados nos casos de infertilidade primária e infertilidade secundária.

\begin{tabular}{|lc|lr|}
\hline \multicolumn{1}{|c|}{$\begin{array}{c}\text { Infertilidade primária }-36 \text { casos } \\
\text { Laudos alterados }-13\end{array}$} & \multicolumn{2}{c|}{$\begin{array}{c}\text { Infertilidade secundária }-12 \text { casos } \\
\text { Laudos alterados }-5\end{array}$} \\
\hline Achados & $\mathrm{N}^{0}$ & Achados & $\mathrm{N}^{0}$ \\
\hline Útero arqueado & 2 & Obstrução tubária unilateral & 2 \\
Dilatação da tuba direita & 2 & Hidrossalpinge unilateral & 1 \\
Obstrução tubária bilateral & 2 & Obstrução tubária bilateral & 1 \\
Sinéquia uterina total & 1 & Salpingite bilateral & 1 \\
Mioma intramural & 1 & & \\
Hidrossalpinge bilateral com obstrução & & & \\
da tuba direita & 1 & & \\
Obstrução tubária com útero septado & 1 & & \\
Adenomiose ou salpingite ístmica nodo- & & & \\
sa na tuba direita, com obstrução par- & & & \\
cial da tuba esquerda & 1 & & \\
Útero bicorno & 1 & \\
Obstrução bilateral com salpingite íst- & & \\
mica nodosa & 1 & & \\
\hline
\end{tabular}

Obs.: Houve ainda um caso em que o exame para investigação de infertilidade primária apresentou laudo que colocava a possibilidade de presença de mioma.

Considerando os exames alterados encontrados, estes foram divididos conforme se vê na Tabela 1 .

\section{DISCUSSÃ O}

O exame de histerossalpingografia tem sido muito utilizado em nosso meio para pesquisa de causas de infertilidade. É um exame sensível às alterações anatômicas da cavidade uterina e das trompas. Muitas vezes, os achados da histerossalpingografia são específicos e podem ser interpretados como causa de infertilidade, o que podemos notar, por exemplo, nos diagnósticos de obstrução bilateral de trompas, sinéquias extensas da cavidade uterina, útero uni ou bicorno, hidrossalpinge bilateral, endometriose tubária severa. Em outras situações, os achados não podem ser responsabilizados pela infertilidade da paciente com $100 \%$ de certeza, o que ocorre quando encontramos obstrução tubária unilateral, salpingite ístmica nodosa (endometriose tubária) leve, útero arqueado, entre outros. Em tais casos, deve-se atribuir causalidade aos achados apenas se descartadas todas as outras possibilidades de infertilidade.

Com relação aos resultados do estudo, podemos observar que a quase totalidade dos achados no exame das pacien- tes com infertilidade secundária se deveram a infecção (cinco casos de infecção em 12 pacientes). Já nas pacientes com infertilidade primária, somente cinco de 36 casos examinados obtiveram laudo compatível com infecção (obstrução, hidrossalpinge).

No que tange às pacientes com infertilidade secundária, não houve laudo compatível com alteração anatômica, ao contrário das pacientes com infertilidade primária, que apresentavam seis laudos com esse tipo de anormalidade. Certamente, a ausência aparente de alterações anatômicas permitiu que as pacientes com infertilidade secundária já tivessem gestado alguma vez.

De acordo com a literatura médica, as causas de infertilidade podem ser divididas em masculinas (40\% a $50 \%$ ), ovulatória $(30 \%)$, uterina ou tubária $(20 \%)$ e imunológica $(5 \%)^{(4,6)}$, ou seja, pode-se dividir as causas de infertilidade em aproximadamente $50 \%$ como masculinas e $50 \%$ como femininas. Sendo assim, poderíamos esperar que, dos 48 exames realizados, aproximadamente 24 apresentassem alterações responsáveis pela infertilidade, o que pôde ser verificado em 18 ocasiões.

Sabendo que nos países de terceiro mundo a causa mais freqüente de infertilidade feminina deve-se a infecções por 


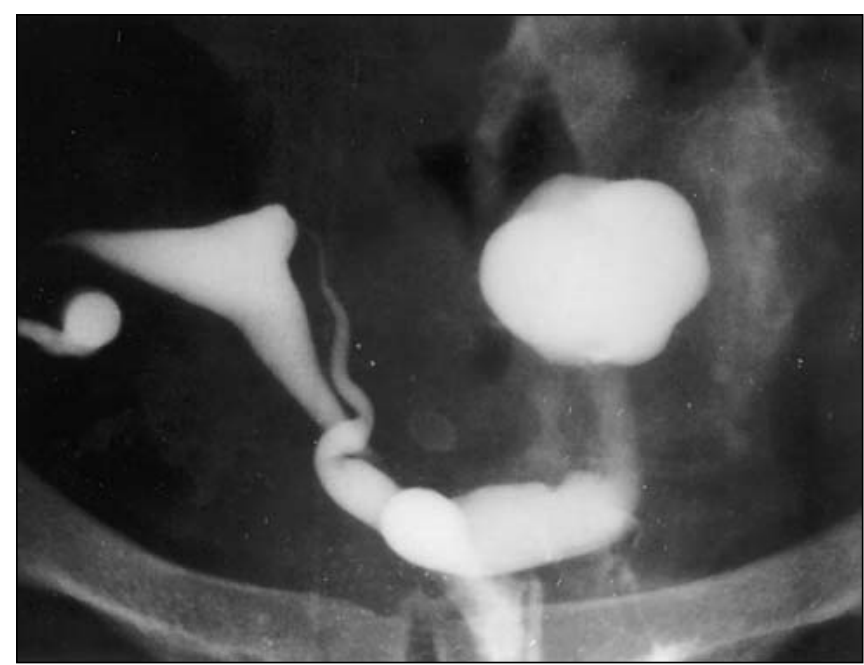

Figura 1. Hidrossalpinge bilateral com obstrução tubária.

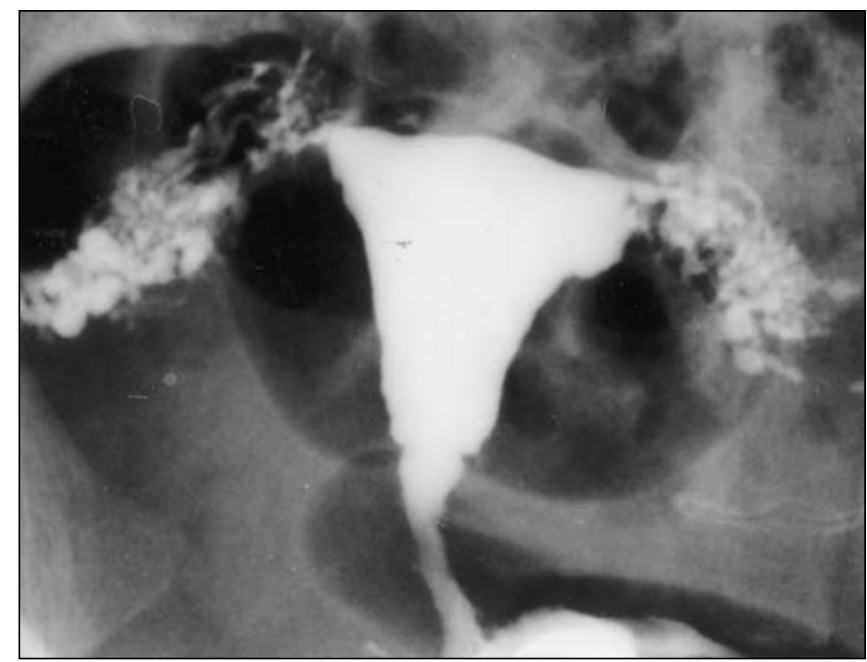

Figura 2. Salpingite ístmica nodosa bilateral.

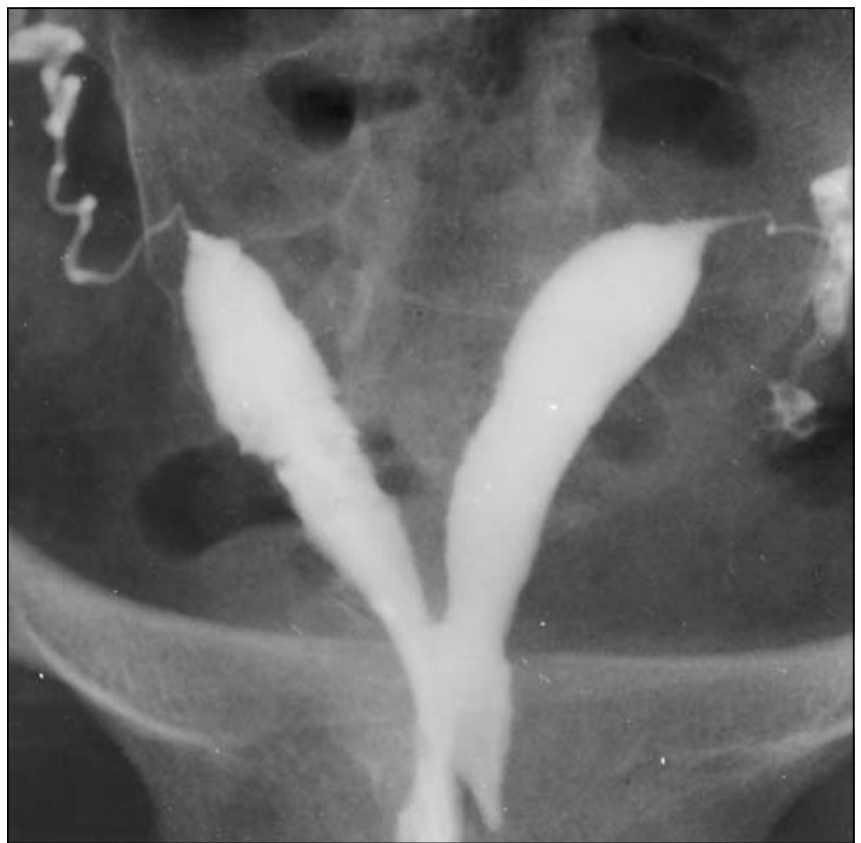

Figura 3. Útero bicorno unicolis.

germes de baixa virulência, como, por exemplo, a Chlamydia trachomatis, responsável por inflamação crônica e silenciosa das trompas, esperaríamos uma prevalência superior dos achados correspondentes à infecção nos exames que se mostraram alterados nas pacientes com infertilidade primária. Como podemos observar, os achados compatíveis com infecção das trompas, obstrução e dilatação (hidrossalpinge) destas apresentaram prevalência de apenas $38,5 \%$, considerando os 13 exames alterados. Talvez isto reflita a diminuta freqüência deste tipo de infecção em nosso meio, comparada a outros locais do País.

\section{CONCLUSÃO}

O exame de histerossalpingografia tem sido muito utilizado em nosso meio para pesquisa de causas de infertilidade. É um exame sensível às alterações anatômicas da cavidade uterina e das trompas. Seu baixo custo e seu pequeno risco de complicações ou intercorrências tornam o exame ainda mais atraente para a avaliação inicial das queixas de infertilidade.

\section{REFERÊNCIAS}

1. Karasick S. Hysterosalpingography. Urol Radiol 1991;13:67-73.

2. Collins JI, Woodward PJ. Radiological evaluation of infertility. Semin Ultrasound CT MR 1995; 16:304-16.

3. Sutton D, Whitehouse RW, Jenkins JPR, Davies ER, Murfitt J, Lees WR. Textbook of radiology and imaging. 6th ed. New York: Churchill Livingstone, 1998:1265-72.

4. Freitas F, Menke CH, Rivoire W, Passos EP. Rotinas em ginecologia. $3^{\mathrm{a}}$ ed. Porto Alegre: Artes Médicas, 1997;92:317-26.

5. Mosher WD, Pratt WF. Fecundity and infertility in the United States, 1965-1988. Advanced data from vital and health statistics. Hyattsville: National Center for Health Statistics, 1990.

6. Van den Eede B. Investigation and treatment of infertile couples: ESHRE guidelines for good clinical and laboratorial practice. European Society of Human Reproduction and Embryology. Hum Reprod 1995;10:1246-71. 